\section{Importance of feedback loops between soil inorganic nitrogen and microbial communities in the heterotrophic soil respiration response to global warming}

\author{
Chonggang Xu, Chao Liang, Stan Wullschleger, Cathy Wilson and \\ Nathan McDowell
}

In their recent article (Microorganisms and climate change: terrestrial feedbacks and mitigation options. Nature Rev. Microbiol. 8, 779-790 (2010) $)^{1}$, Singh et al. pointed out that the mechanistic basis for predicting the greenhouse gas fluxes under climatic change lies in a detailed understanding of how abiotic and biotic factors affect microbial community dynamics and functions. They highlight that, owing to the vast unexplored diversity of microbiota and the large uncertainty regarding microbial community responses to global change, there are currently no earth system models that have incorporated microbial community dynamics.

We strongly agree with Singh et al. and wish to further highlight that the feedback loop between inorganic nitrogen dynamics and microbial communities (steps $2-4$ in FIG. 1) can play a key role in regulating the heterotrophic soil respiration response to global warming, and that this is an important mechanism to be incorporated into global earth system models. For high-latitude ecosystems (that is, tundra and boreal ecosystems), the increase in soil temperature with global warming can substantially enhance the activity of microbial communities, and this will lead to faster decomposition of soil organic matter and more inorganic nitrogen in the soil ${ }^{2-3}$ (steps 1-3 in FIG. 1). This increase in the soil concentration of inorganic nitrogen may stimulate the production of cellulose-decomposing enzymes but block the production of lignindecomposing enzymes ${ }^{4}$. These differential effects on enzyme production may lead to an increase in abundance of the copiotrophic community (containing microorganisms that are characterized by a high growth rate on labile carbon and in a nutrient-rich environment) and a decrease in abundance of the oligotrophic community (containing microorganisms that are characterized by a slow growth rate on recalcitrant carbon and in a nutrient-poor environment $)^{5}$ (step 4 in FIG. 1). Finally, the change in microbial community structure can have important feedbacks to the carbon cycle by increasing the turnover rates of labile soil carbon pools but decreasing the turnover rates of recalcitrant carbon pools (step 2 in FIG. 1). Thus, the feedback loop between inorganic nitrogen dynamics and microbial communities (steps 2-4 in FIG. 1) could be a key mechanism of regulating soil carbon storage under projected future warming. We may incorporate this mechanism into earth system models by dividing the microbial community into two functional groups ${ }^{6-7}$ : the oligotrophic community, which mainly targets recalcitrant carbon pools, and the copiotrophic community, which mainly targets labile carbon pools.

Many factors can affect the feedback loop between nitrogen dynamics and microbial communities, including climate, vegetation, carbon quality, permafrost (for arctic regions), nitrogen deposition and fixation,

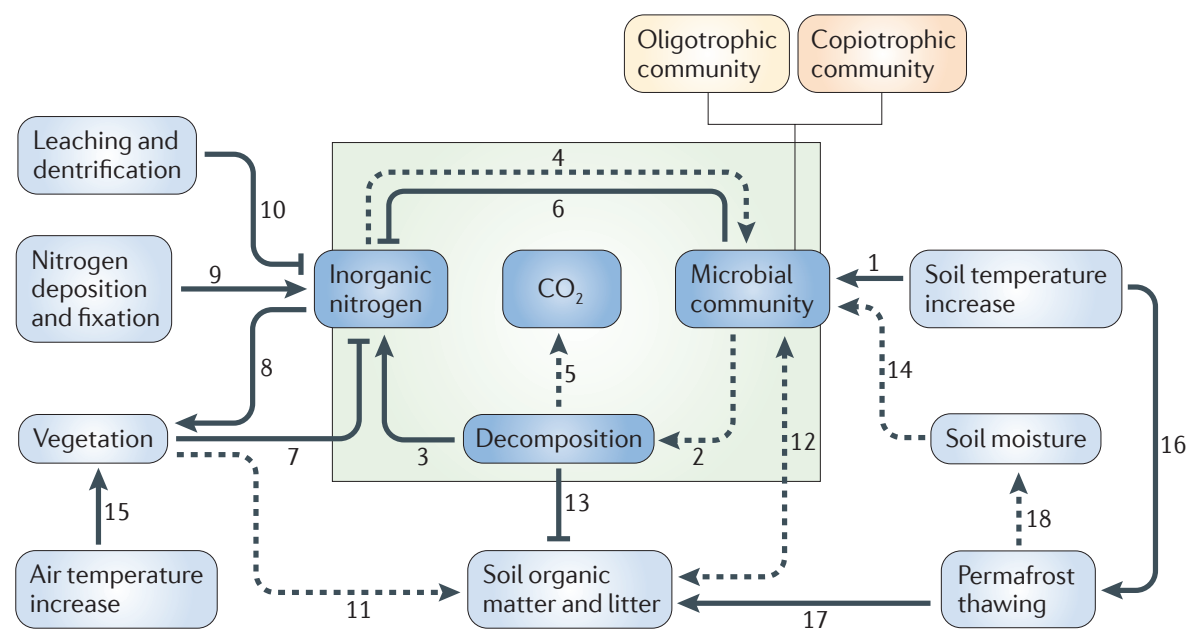

Figure 1 | Feedback loop between inorganic nitrogen dynamics and microbial communities, and related factors in the heterotrophic soil respiration response to global warming in highlatitude ecosystems. 1: soil warming increases the activity of microbial communities. 2: changes in the structure and activity of a microbial community may affect decomposition of soil organic matter and litter. 3: stimulation of microbial decomposition increases the availability of inorganic nitrogen. 4: nitrogen availability can affect microbial community structure and activity. 5: the feedback loop between nitrogen and a microbial community in steps $2-4$ can regulate the heterotrophic soil respiration response to warming. 6: increased microbial biomass may immobilize more inorganic nitrogen and thus reduce the availability of soil inorganic nitrogen. 7 : increased nitrogen uptake by vegetation reduces soil nitrogen availability. 8: an increase in nitrogen availability stimulates vegetation growth. 9: nitrogen deposition and fixation increase the availability of soil inorganic nitrogen. 10: leaching and denitrification reduce the availability of inorganic nitrogen. 11: vegetation responses may modify litter quality and quantity. 12: soil organic matter and litter can affect the structure and activity of the microbial community, whereas microbial residues can be continuously incorporated into soil organic matter pools. 13: microbial decomposition reduces the quantity and quality of soil organic matter. 14: soil moisture affects microbial community structure and activity by changing oxygen availability and the accessibility of soil organic matter. 15: an increase in air temperature stimulates the growth of vegetation. 16: an increase in soil temperature causes permafrost to thaw. 17: permafrost thawing increases the pool of decomposable soil organic carbon. 18: permafrost thawing can modify soil moisture. Solid lines with arrowheads indicate positive feedbacks, whereas those with flat heads indicate negative feedbacks. Dotted arrows indicate either positive or negative feedbacks. Note that, for simplicity, we do not include the organic nitrogen (for example, amino acid) pool in this figure, which could be important for both vegetation and microbial growth. 


\section{CORRESPONDENCE}

and denitrification (FIG. 1). Therefore, to accurately predict soil carbon storage under global warming, we need integrated dynamic ecosystem models of plants, microorganisms and soils, along with a detailed representation of the nitrogen cycle. Although we currently have a good understanding of how nitrogen affects the structure and activity of a microbial community ${ }^{5,8-9}$, further interdisciplinary studies are needed to better understand the feedback loop between inorganic nitrogen dynamics and microbial communities and to better represent the complex plant-microorganism-soil system in global earth system models.

Chonggang Xu, Cathy Wilson and Nathan McDowell are at the Division of Earth and Environmental Sciences, Los Alamos National Laboratory, Los Alamos, New Mexico 187545, USA.
Chao Liang is at the Great Lakes Bioenergy Research Center and Department of Soil Science, University of Wisconsin-Madison, 1525 Observatory

Drive, Madison, Wisconsin 53706, USA.

Stan Wullschleger is at the Environmental Sciences Division, Oak Ridge National Laboratory, Oak Ridge, Tennessee 37831, USA.

Correspondence to C.X.: xuchongang@gmail.com doi:10.1038/nrmicro2439-c1

1. Singh, B. K., Bardgett, R. D., Smith, P. \& Reay, D. S. Microorganisms and climate change: terrestrial feedbacks and mitigation options. Nature Rev. Microbiol. 8, 779-790 (2010).

2. Weintraub, M. N. \& Schimel, J. P. Nitrogen cycling and the spread of shrubs control changes in the carbon balance of arctic tundra ecosystems. Bioscience $\mathbf{5 5}$ 408-415 (2005)

3. Mack, M. C., Schuur, E. A. G., Bret-Harte, M. S., Shaver, G. R. \& Chapin, F. S. Ecosystem carbon storage in arctic tundra reduced by long-term nutrient fertilization. Nature 431, 440-443 (2004).

4. Carreiro, M. M., Sinsabaugh, R. L., Repert, D. A. $\overline{8}$ Parkhurst, D. F. Microbial enzyme shifts explain litter decay responses to simulated nitrogen deposition. Ecology 81, 2359-2365 (2000).
5 Ramirez, K. S Lauber, C. L., Knight, R, Bradford, M. A. \& Fierer, N. Consistent effects of nitrogen fertilization on soil bacterial communities in contrasting systems. Ecology 91, 3463-3470 (2010).

6. Fierer, N., Bradford, M. A. ¿ Jackson, R. B. Toward an ecological classification of soil bacteria. Ecology $\mathbf{8 8 ,}$ 1354-1364 (2007)

7. Miki, T., Ushio, M., Fukui, S. \& Kondoh, M. Functional diversity of microbial decomposers facilitates plant coexistence in a plant-microbe-soil feedback model. Proc. Natl Acad. Sci. USA 107, 14251-14256 (2010).

8. Waldrop, M. P., Zak, D. R. \& Sinsabaugh, R. L. Microbial community response to nitrogen deposition in northern forest ecosystems. Soil Biol. Biochem. 36 1443-1451 (2004).

9. Janssens, I. A. et al. Reduction of forest soil respiration in response to nitrogen deposition. Nature Geosci. 3, 315-322 (2010).

\section{Acknowledgements}

This work is funded by the US Department of Energy Office of Science, Office of Biological and Environmental Research (BER) Program.

Competing interests statement

The authors declare no competing financial interests. 